\title{
COVID19: An Opinion on Animal Infections and Role of Veterinarians in One Health Perspective
}

\author{
Swagatika Priyadarsini ${ }^{1 *}$, Rohit Singh ${ }^{2}$, Arun Somagond ${ }^{3}$ and Puja $\mathrm{Mech}^{4}$ \\ ${ }^{1}$ Division of Biochemistry, Indian Veterinary Research Institute, Bareilly, UP, India \\ ${ }^{2}$ Division of Pathology, Indian Veterinary Research Institute, Bareilly, UP, India \\ ${ }^{3}$ Livestock Production and Management, Indian Veterinary Research Institute, Bareilly, UP, India \\ ${ }^{4}$ Division of Bacteriology, Indian Veterinary Research Institute, Bareilly, UP, India \\ *Corresponding author mail address: drswagatika.vet@gmail.com
}

\begin{abstract}
Coronavirus disease is the current cause of global concern. The massive outbreak of COVID-19 has led the World Health Organization (WHO) to declare this as a pandemic situation. The Severe Acute Respiratory Syndrome Coronavirus-2 (SARSCoV-2) is responsible for COVID-19 leading to acute respiratory distress and substantial mortality in humans. However, the first laboratory confirmation of SARS-CoV-2 in a pet dog in Hong Kong has shown the possibility of human-to-animal transmission (zooanthroponotic) of the virus. Thereafter, many animals including cat, tiger, lion and mink have also been reported to acquire the virus in several countries. In this situation the role of veterinarian assumes important in treating the animals, helping in food security, disease diagnosis, surveillance and boosting the economy of livestock stakeholders at the grassroot level. In the absence of any selective vaccine or drug against SARS-CoV-2, the world is anticipated to triumph over this pandemic with collaborative, multisectoral, and transdisciplinary approach linking human, animal and environmental health. This article gives an insight into the confirmed SARS-CoV-2 outbreaks in animals, including the factors behind the shuffling of the virus among variety of species and also emphasizes on the role of veterinarian in managing and safeguarding public health so as to pave the way for adopting one health approach in order to conserve biodiversity.
\end{abstract}

Key words: COVID-19, SARS-CoV-2, zoonoses, anthroponosis, veterinarian, OIE and animals.

\section{Introduction}

The current global population is going through the worst of its health emergency as every human is either directly or indirectly fighting against the emerging pandemic Corona Virus Disease-2019 (COVID-19). The pandemic caused by a new coronavirus (CoV) was named earlier as 2019 novel Coronavirus (2019-nCoV) ${ }^{22}$ but later, on 11th February 2020, its new nomenclature was formulated by the Coronavirus Study Group (CSG) of International Committee on Taxonomy of Viruses (ICTV) as "Severe Acute Respiratory Syndrome Coronavirus 2 (SARS-CoV-2)" and the disease was termed as "COVID-19" 29 . This virus has also been reported to cause unusual pneumonia in the affected patients ${ }^{6}$. Till date $\left(20^{\text {th }}\right.$ June 2020), the total COVID-19 cases in humans count to $83,85,440$ with a case fatality rate of 5.37 $\%{ }^{35}$. Now, the SARS-CoV-2 infection is not only limited to humans, rather the disease was observed to cross the species boundary by affecting different several species of animals. Although there are speculations about the origin of this disease and is traced to two different animals: bat and pangolin ${ }^{39,40}$, marking the disease as zoonotic. Studies are underway around the globe to confirm the evidence behind the source of virus contraction by human.

COVID-19 is hypothesized to be stemmed from the clients of the Wuhan's "wet market" (where both live and dead wild animals, reptiles and birds are sold and slaughtered) in Hubei province, China. The first hospitalized case with a mysterious etiology was reported on 
8th Dec 2019. On Jan 7, 2020, a novel CoV was found to be its etiological agent. On January 30, 2020 the WHO declared this as the "public health concern of international emergency". Later, on March 11, 2020 WHO changed the disease status to "pandemic" 38. Thereafter the disease spread across the globe affecting the population of 216 countries and territories combinedly as updated on 20th June 2020 (WHO, 2020).

Looking at the spontaneous surge in cases, the question arises whether veterinarians are to be included in public health management. Nevertheless, animals have been an integral part of human life from time immemorial. From providing food, as companion animals to maintaining ecological balance, they have had a varied role to play in human life. With consideration of the above facts, it is high time to focus on the confirmed cases of SARS-CoV2 in cats, mink, tiger, dog and lion, being reported worldwide ${ }^{19,40}$. But the fact that as human infections subside, the establishment of SARS-CoV-2 in wild or pet animals may lead to reverse transmission of the disease from animals to human in near future. Therefore, the purpose of this article is to briefly outline the veterinary importance of CoVs and summarize the confirmed cases of SARS-CoV-2 positive animals to date. In addition, an attempt has also been made to delineate the factors behind the shuffling of the virus among a variety of species and narrate the vital roles of veterinarians in managing and safeguarding public health.

\section{Coronavirus diseases in veterinary perspective}

CoVs belong to the family Coronaviridae, the subfamily Coronavirinae and the order Nidovirales as per the ICTV. Based on phylogenetic relationships and genomic structures, four genera namely, Alphacoronavirus, Betacoronavirus, Gammacoronavirus and Deltacoronavirus are grouped under the subfamily Coronavirinae ${ }^{14}$. Amid these four genera, mammals can be infected by alpha- and beta CoVs, however, gamma- and delta CoVs specifically infect birds ${ }^{38,6}$. Two genera Tonovirus and Bafinivirus belong to Tonovirinea family and they cause diseases in aquatic organism.

$\mathrm{CoV}$ is a long-established infectious pathogen of veterinary importance. Bovine corona virus $(\mathrm{BCoV})$ belongs to the Coronaviridae family and order Nidovirales affects the respiratory and gastrointestinal systems causing winter dysentery in adults, calf diarrhoea in neonates and respiratory infection in cattle ${ }^{27,37}$. Feline infectious peritonitis viruses (FIPV) and feline enteric coronaviruses (FECV) are the two biotypes of the Feline coronavirus (FCoV). The earlier virus causes asymptomatic enteric infection in feline, while the latter causes fatal disease in the domestic and wild Felidae ${ }^{32}$. Canine $\mathrm{CoV}$ causes mild self-limiting gastroenteritis in adult dogs while highly virulent strain pantropic canine corona virus causes lethal systemic infection in the pups ${ }^{10,3}$. Some Corona viruses infecting dogs can involve tracheobronchitis ${ }^{11}$. The Porcine Epidemic Diarrhoea Virus (PEDV) and Transmissible Gastroenteritis Virus (TGEV) belonging to the genus Alphacoronavirus, causes severe diarrhoea in swine population ${ }^{28,31}$.

Re-emerging and emerging CoVs include Porcine Deltacoronavirus (PDCoV) and Porcine Epidemic Diarrhoea Virus (PEDV) ${ }^{34}$. Swine acute diarrhoea syndrome corona virus (SADS-CoV) found to be originated from the bat and sparrow causes acute gastroenteritis in the new born piglets ${ }^{34}$. Equine Coronavirus (ECoV) of the genus Betacoronavirus, has been found to be associated with the neurological, enteric and pyrogenic disease in equines ${ }^{13}$. Infectious Bronchitis Virus (IBV) associated with acute upper respiratory tract infection and nephritis in chicken belongs to the Coronaviridae family ${ }^{7}$. Even wild aquatic birds are also found to be infected by avian corona viruses ${ }^{5}$. Also, lab animals like mice and the golden Syrian hamsters can contract Mouse hepatitis virus (MHV) associated with acute encephalitis and SARS infection respectively ${ }^{1,24}$.

$\mathrm{CoV}$ infections have also been reported in the aquatic animals. Viruses belonging to the genus Alphacoronavirus, Gammacoronavirus, Tonovirus, and Bafinivirus infect the aquatic 
organisms. The corona virus infection was reported in three harbour seals (Phoca vitulina), which died due to the acute necrotizing enteritis ${ }^{2}$. Pathological examination of the lung revealed severe diffuse pulmonary congestion, focal bronchoalveolar haemorrhages and oedema in alveoli. Positive immunofluorescence reaction with the antibody against TGEV, FIPV, CCoV confirms etiological agent as a alphacoronavirus ${ }^{2}$.

Beluga whale coronavirus SW1 (BWCoV SW1) belonging to the genus Gammacoronavirus isolated from the captive-born beluga whale developed generalized pulmonary infection and died due to liver failure ${ }^{17}$. Subsequently, Bottle nose dolphin (BdCoV HKU22) coronavirus was detected in the faeces of the Indo-Pacific bottlenose dolphins ${ }^{35}$. However, BdCoV HKU22 causes asymptomatic or mild infection in comparison to the BWCoV SW1. Furthermore, white brim virus (WBV), belongs to the genus Bafinivirus within the Nidovirale order, was isolated from the healthy white brim and was found to be closely related with the genus Tonovirus in comparison to the other genera of Nidovirales order ${ }^{15}$.

\section{Zoonotic perspective}

A recent study suggested that bats are the class of mammals which possess the highest acceleration in evolving the acetylcholine esterase-2 (ACE2) receptor for binding to the spike protein of $\mathrm{CoV}^{8}$. Hence this mammal represents the primary reservoir for most of the outbreaks in the last two decades (Fig-1). An in-silico scrutiny was conducted to know cross-species conservation of the ACE-2 receptor in 410 vertebrates including 250 mammals, which was supposed to be helpful for the selection of the animal model for COVID-19 ${ }^{8}$. Besides, he scored the binding of COVID-19 with ACE-2 receptor as very high, medium, low and very low to predict susceptible species which can get infected in the COVID-19 pandemic. This analysis predicted a very high score for the binding of SARS-CoV-2 spike protein with ACE-2 of Macaca mulatta. This was supported by the finding in naturally infected Macaca mulatta in which COVID-19-like symptoms developed ${ }^{18}$. The bats remained as natural reservoirs for the two high profile human CoV outbreaks such as SARS-CoV and MERS-CoV in the past, where the wild civets and camels were thought to be the intermediate hosts respectively for the transmission of these two viruses to humans ${ }^{16}$. Although the world is still uncertain about the origin of human infection of SARS-CoV-2, significant genetic similarities were claimed to be existing among the CoVs of humans with that of bat and pangolin. Phylogenetic analysis performed 96.2\% identity among the SARS-CoV-2 and RaTG13-CoV of Rhinolophus affinis bat were found ${ }^{40}$. Later, about $91.02 \%$ nucleotide identity was found among SARS-CoV-2 and the $\mathrm{CoV}$ of Malayan pangolins (Manis javanica), hence suggesting this animal as an intermediate host for human infection ${ }^{39}$.

Currently the disease is getting transmitted among humans via droplet infection 25 . Many researchers also argue for the existence of faeco-oral transmission of the virus as SARSCoV-2 have been found in faecal samples of patients ${ }^{21,38}$. But the spread of disease by animal food consumption is not yet confirmed.

Now, the question arises whether veterinarians are required to be alert for the current global pandemic. This question can easily be answered by looking at the outbreak of SARSCoV-2 which has already been reported in animals. Unlike the previous outbreaks of SARS and MERS, SARS-CoV-2 has already been shown to be acquired by many animal species from human interactions.

\section{SARS-CoV-2 anthroponosis (human-to-animal transmission)}


The first case of contracting the disease from its owner was a pet dog at Hong Kong, China, on 28th February 2020. Fortunately, after taking proper isolation and quarantine measures the dog tested negative to the virus neutralization test conducted on 12 March 2020. The cases reported in the animals worldwide are summarized in a table (Table1).

Results from laboratory experiments concluded that cats are most susceptible to SARSCoV-2 followed by ferrets. Dogs, pigs and ducks are not susceptible to SARS-CoV- $2^{30}$. According to OIE, the cats, ferrets and dogs show clinical signs in severe to mild forms respectively, but there is no observation of any disease symptoms in fruit bats.

After all these spontaneous outbreaks of SARS-CoV-2 in animals, OIE categorized the disease as one of the "emerging diseases" ${ }^{19}$. In all the above cases, "direct contact" between human and animal has been established as the route of disease transmission.

\section{Factors responsible for broad host range of Coronavirus:}

The foremost reason can be that among all RNA viruses, CoV has the highest segmented RNA genome (approx. 30kb), which can be a cause behind its shuffling between numerous host species ${ }^{33}$.

Among four structural genes of SARS-CoV-2: spike (S), envelope(E), membrane (M) and nucleocapsid gene $(\mathrm{N})$, the first one encodes for spike protein which lies in the receptor binding domain of virus. Spike protein (SRAS-CoV-2 S) is further processed to form a glycoprotein and is expressed on the surface of viral capsid. This glu ${ }^{394}$ of spike protein attaches and binds to the $1 y s^{31}$ amino acid of ACE2 receptor and act as the entry point of host cell infection $^{33}$. Previous studies on 2002-SARS outbreak also concluded that the major genetic alterations in the gene responsible for encoding spike protein has transcended the transmission of SARS-CoV from animal to human beings ${ }^{31}$.

Atomic structural resolution of the complex formed by SARS-CoV-2 ' $\mathrm{S}$ ' and the ACE2 receptor of several species revealed that the ACE2 receptor of animals like "pigs, ferrets, cats and nonhuman primates" are either equally or more susceptible to the receptor binding domain (RBD) of spike protein of SARS-CoV-2 than that of human ${ }^{33}$. In silico analysis of ACE2 receptor of 410 vertebrates suggests that SARS-CoV-2 can potentially have a variety of species either as its reservoir or intermediate hosts while the old world primates are at high risk of getting susceptible to this virus ${ }^{8}$.

\section{Diagnosis in animals}

In all the confirmed veterinary cases of SARS-CoV-2, the samples collected for examination were either vomit, rectal swab, nasal swab or feces (OIE, 2020). Since the cases reported were from different developed countries, most of the laboratory confirmation was by real-time reverse transcriptase polymerase chain reaction (RT-PCR) mostly targeting the Ngene of virus and few by next generation sequencing of viral DNA. Centers for Disease Control and Prevention ${ }^{4}$, USA recommends that combination of "fever, coughing, difficulty breathing/shortness of breath, lethargy, sneezing, nasal/ocular discharge, vomiting and diarrhoea" are the symptoms related to infection with SARS-CoV-2 in pets. However, veterinarians should perform extensive differential diagnosis of the patient before recommending for laboratory testing of SARS-CoV-2, as the availability of kits is limited. CDC also directs veterinarians to recommend laboratory testing of animals only after a thorough discussion with state "public health authorities" providing requisite justice to "One Health" (health of people is connected to the health of animals and our shared environment).

\section{Prevention and Control}


Animal-to-animal and animal-to-human transmission of SARS-CoV-2 is not yet established but few cases of human-to-animal transmission are reported in many countries. Therefore, veterinary staffs either with feverish or other symptoms of COVID-19 should not handle the animal. Nevertheless, in urgent cases of animal handling by a sick veterinarian should follow proper handwashing and face-covering of the personnel to contain the spread of infection. As suggested in the case of humans, only emergency veterinary surgeries should be performed during this period. The government should both legalise and promote veterinary telemedicine facilities in the country as well to reduce the frequency of visiting polyclinics. Contact and epidemiological history of the patient and the owner should be noted down by the staff before treatment. Every government and private veterinary hospital should maintain an isolation room or space to handle both suspected as well as confirmed patients.

It has been found that in case of humans the SARS-CoV-2 can spread to different systems like the respiratory, digestive, urinary and haematological system of COVID-19 patient and the virus can shed to the environment via either urine, stool or sputum ${ }^{20}$. Therefore, veterinarians should perform an autopsy of either naturally or experimentally infected animals thoroughly for examining the dissemination of virus to different organs, which could discover the possible routes of shedding virus by animals. SARS-CoV-2 viruses have been found in feces and vomit samples obtained from infected animals (Table 1). The situation may worsen if any of the street animals acquires and start shedding the virus. Hence justifying the argument of conducting animal surveillance in the area where community spread is obvious.

Appropriate steps of donning and doffing of personal protective equipment (PPE) should be followed by the veterinarians and staffs while handling the patient. The veterinarians while treating any patient must strictly adhere to biosafety and biosecurity measures.

Veterinary surgeons who continue to work during the pandemic should remain updated with all the guidelines formulated by the animal husbandry department of their respective countries and also the OIE. It should be the sole responsibility of veterinarians to alert livestock, pet owners and zoo employees at the grassroot level.

\section{Roles and responsibilities of the veterinary professionals towards public health}

Many countries have started imposing lockdown as a preventive measure to tackle the pandemic which resulted in closure of travel, businesses and numerous public services. Concurrently few essential services are still open for the public which also includes veterinary services to keep up the health and welfare of animals. Veterinarians are engaged in the diagnosis, treatment and prevention of diseases in livestock, pets, birds and wild animals (Fig2). They are also involved in organizing vaccination and deworming camps. On top of that various other crucial roles are still pertaining on behalf of them. We would like to throw light on the activities where veterinarians could render their help in fighting COVID-19.

Veterinary microbiologists and biotechnologists can be trained and recruited in laboratories for human sample collection and their screening. Apart from safeguarding animals by prevention of outbreaks and zoonoses, veterinary epidemiologists can suggest surveillance measures from their experiences from several animal epidemics (avian influenza, rinderpest, bluetongue etc.) occurred in the past ${ }^{12}$.

SARS-CoV-2 transmission via food consumption has not been established yet. But amid consumers' fear of acquiring COVID-19 by animal food consumption, proper food processing and inspection is the need of the hour. Heparan sulfate, a negative charged glycosaminoglycan is rich in animal meat and is hypothesized to be the eligible anchor for spike protein of SARS$\mathrm{CoV}-2^{23}$. Hence, veterinarians should properly inspect animal food and spread awareness among public against their fear which will be able to possess significant epidemiological implication to ensure safe maintenance of the food chain. Besides, management of zoo animals 
and threatened species by veterinarians necessitates a noteworthy attention as the disease has already been observed to be reported in tiger and lion $^{40}$.

As speculated by economists, this pandemic may negatively impact the world economy due to the shutdown of several factories, businesses, construction work etc. Many people lost their jobs temporarily/permanently and have started returning to their native place. At the grassroot level, veterinarians can be engaged in advising farmers and for raising livestock and managing farms. This can reopen the source of income to the unemployed section and restore the country's economy.

Ultimate anticipation of all the global citizens is the discovery of a vaccine against SARSCoV-2. Human vaccine development includes various stages of clinical trials which involves animal trials too. Ferrets and hamsters are two animal models, recently suggested by the OIE, for testing of vaccines and drugs against SARS-CoV-2 ${ }^{19}$. Beginning with the management of laboratory/experimental animals, developing animal models for virus pathogenesis study to vaccine trials, veterinarians are to be prioritized in all these domains. Apart from the above, veterinary researchers can be appointed for human vaccine manufacturing as they have well expertise in the cutting-edge health associated molecular techniques.

A surge in the number of cases of SARS-CoV-2 in animals is well observed and calls for in-depth experiments to develop vaccine and diagnostic kits for susceptible animals as well. Currently many veterinary colleges and research institutes, those are equipped with biosafety level -3 (BSL-3) and real-time PCR machines, are involved in processing and screening human samples for SARS-CoV-2. As the world is still not confident to support the fact that bat or pangolin as the reservoir of SARS-CoV-2, more of the research and surveillance by veterinarians is essential for exploring the accurate source of the disease. This can help in building a boundary between the reservoir and human as a measure of prevention of further outbreak. Veterinary vaccine manufacturers and pharmaceutical companies can be considered for production of human vaccines and antiviral drugs respectively in huge quantities. At the end but not the least, veterinary clinics can support the medical health facilties by donating essential materials such as personal protective equipments and ventilators.

\section{Role of OIE-World Organisation for Animal Health:}

OIE is the apex organization responsible for safeguarding the animal heath worldwide. The organization coordinates with its regional representatives as well as food and animal organization (FAO) and WHO, to gather information and further share the same with its members and it also monitors the rumors and unofficial information on daily basis. The organization mobilizes several technical working groups ('ad hoc groups') to provide scientific advice on research activities and other implications of COVID-19 on animal health. Further it guides veterinary laboratories working with public health services to support testing of human samples for SARS-CoV-2 with regard to contain the ongoing pandemic. Apart from protecting the domesticated and companion animals and birds, the organization also works with its Wildlife Working Group and other partners to develop a longer-term plan which objective of understanding the dynamics and risks involved in wildlife trade and consumption.

\section{Conclusion and prospects}

The origin of SARS-CoV-2 infection in human has not been clearly established yet, however human-to-animal transmission has been well observed in all the reported cases and thus may claim the disease as anthroponosis in near future. Hence there may be a surge in the asymptomatic reservoirs and carriers of the virus in the environment that may possibly lessen the chance of limiting the spread of this pandemic. In this scenario many important aspects like 
food safety, disease diagnosis, prevention of outbreak in human and animals and safeguarding public health etc. play crucial roles in our society and the adoption of suitable public health preventive measures and strengthening medical facilities are the best options for managing the disease. This can only be achieved successfully by including veterinarians in the global health system during this pandemic.

With respect to animal health, companion animals of COVD-19 infected owners should be quarantined and may be recommended for screening for the presence of virus. All zoo keepers should be scanned for the disease before contacting the zoo animals. Army dogs are the most expensive and are also the integral part of the country's security, hence their surveillance is utmost important. Veterinary department of all territories should take the responsibility of reporting the detailed information of all confirmed cases of animals to WOAH, OIE within the earliest time. To combat this pandemic, the country's legislation should act vigorously considering the "One Health" approach to conserve the biodiversity by acting synchronously towards welfare of human and animal health combinedly.

\section{Ethics approval and consent to participate}

Not applicable

\section{Consent for publication}

Not applicable

Availability of data and material

Not applicable

\section{Competing interests}

The authors declare that they have no competing interests

\section{Funding}

Not applicable

\section{Authors' contributions}

SP formulated the idea, collected data and wrote the draft. PM prepared the table, RS prepared figures and the table. AS collected data and corrected the grammar of the manuscript. All authors read and approved the final manuscript

\section{Acknowledgements}

Not applicable 
Table 1: List of animals tested positive for SARS-CoV-2

\begin{tabular}{|c|c|c|c|c|c|}
\hline $\begin{array}{l}\text { S. } \\
\text { No }\end{array}$ & $\begin{array}{l}\text { Month of } \\
\text { outbreak }\end{array}$ & $\begin{array}{c}\text { Confirmed } \\
\text { veterinary case }\end{array}$ & Place & Clinical signs & Test \\
\hline 1 & $\begin{array}{l}\text { February, } \\
2020\end{array}$ & Dog & $\begin{array}{l}\text { Hong Kong, } \\
\text { China }\end{array}$ & No symptoms & Real-time RT-PCR \\
\hline 2 & March, 2020 & Dog & $\begin{array}{l}\text { Hong Kong, } \\
\text { China }\end{array}$ & No symptoms & Gene sequencing \\
\hline 3 & March, 2020 & Cat & Belgium & Respiratory symptom & Gene sequencing \\
\hline 4 & April, 2020 & Cat & $\begin{array}{l}\text { New York, } \\
\text { USA }\end{array}$ & Respiratory symptom & $\begin{array}{l}\text { Real-time RT-PCR and } \\
\text { gene sequencing }\end{array}$ \\
\hline 5 & April, 2020 & Cat & $\begin{array}{l}\text { New York, } \\
\text { USA }\end{array}$ & Respiratory symptom & $\begin{array}{l}\text { Real-time RT-PCR and } \\
\text { gene sequencing }\end{array}$ \\
\hline 6 & May, 2020 & Cat & France & Respiratory symptom & Real-time RT-PCR \\
\hline 7 & April, 2020 & Mink & Netherland & Gastrointestinal and respiratory symptom & PCR \\
\hline 8 & April, 2020 & Tiger & $\begin{array}{l}\text { New York, } \\
\text { USA }\end{array}$ & Dry cough, wheezing and inappetence & $\begin{array}{l}\text { Real-time RT-PCR and } \\
\text { gene sequencing }\end{array}$ \\
\hline 9 & April, 2020 & Tiger & $\begin{array}{l}\text { New York, } \\
\text { USA }\end{array}$ & Dry cough, wheezing and inappetence & $\begin{array}{l}\text { Real-time RT-PCR and } \\
\text { gene sequencing }\end{array}$ \\
\hline 10 & April, 2020 & Lion & $\begin{array}{l}\text { New York, } \\
\text { USA }\end{array}$ & Dry cough, wheezing and inappetence & $\begin{array}{l}\text { Real-time RT-PCR and } \\
\text { gene sequencing }\end{array}$ \\
\hline 11 & May, 2020 & Cat & Spain & $\begin{array}{c}\text { Dyspnoea, tachypnea, thrombocytopenia and } \\
\text { hypertrophic cardiomyopathy }\end{array}$ & Real-time RT-PCR \\
\hline \multirow{2}{*}{$\begin{array}{l}12 \\
13\end{array}$} & May, 2020 & Cat & Germany & No symptoms & PCR \\
\hline & May, 2020 & Two Mink farms & Netherlands & No symptoms & PCR \\
\hline 14 & May, 2020 & Domestic cat & Russia & No symptoms & RT-PCR \\
\hline 16 & June, 2020 & Mink farm & Denmark & No symptoms & NA \\
\hline
\end{tabular}

Source: https://www.oie.int/en/scientific-expertise/specific-information-and recommendations/questions-andanswers-on-2019novel-coronavirus/

\section{References:}

1. Bender SJ, Weiss SR (2010) Pathogenesis of murine coronavirus in the central nervous system. J Neuroimmune Pharmacol 5:336-54

2. Bossart GD, Schwartz JC (1990) Acute necrotizing enteritis associated with suspected coronavirus infection in three harbor seals (Phoca vitulina). J Zoo Wildlife Med 84-7

3. Buonavoglia C, Decaro N, Martella V, Elia G, Campolo M, Desario C, Castagnaro M, Tempesta M (2006) Canine coronavirus highly pathogenic for dogs. Emerg Infect Dis $12: 492.3$

4. CDC: https://www.cdc.gov/coronavirus/2019-ncov/daily-life-coping/animals.html Accessed on 15 Jun 2020

5. Chu DK, Leung CY, Gilbert M, Joyner PH, Ng EM, Tsemay MT, Guan Y, Peiris JS, Poon LL (2011) Avian coronavirus in wild aquatic birds. J Virol 85:12815-20

6. Chen Y, Liu Q, Guo D (2020) Emerging coronaviruses: genome structure, replication, and pathogenesis. Journal of medical virology 92(4):418-23

7. Cong F, Liu X, Han Z, Kong X, Liu S (2013) Transcriptome analysis of chicken kidney tissues following coronavirus avian infectious bronchitis virus infection. BMC Genomics 14:743

8. Damas J, Hughes GM, Keough KC, Painter CA, Persky NS, Corbo M, Hiller M, Koepfli KP, Pfenning AR, Zhao H, Genereux DP (2020) Broad Host Range of SARSCoV-2 Predicted by Comparative and Structural Analysis of ACE2 in Vertebrates. bioRxiv. Jan 1

9. Decaro N, Buonavoglia C (2008) An update on canine coronaviruses: viral evolution and pathobiology. Vet Microbiol 132:221-34

10. Dhama K, Patel SK, Pathak M, Yatoo MI, Tiwari R, Malik YS, Singh R, Sah R, Rabaan AA, Bonilla-Aldana DK, Rodriguez-Morales AJ (2020) An update on SARS-CoV- 
2/COVID-19 with particular reference to its clinical pathology, pathogenesis, immunopathology and mitigation strategies. TRAVEL MED INFECT DI 30:101755

11. Ellis $\mathbf{J}$ (2019) What is the evidence that bovine coronavirus is a biologically significant respiratory pathogen in cattle? La revue veterinaire canadienne 60:147-52

12. Foddai A, Lubroth J, Ellis-Iversen J (2020) Base protocol for real time active random surveillance of coronavirus disease (COVID-19)-Adapting veterinary methodology to public health. One Health 100129

13. Giannitti F, Diab S, Mete A, Stanton JB, Fielding L, Crossley B, Sverlow K, Fish S, Mapes S, Scott L, Pusterla (2015) N.Necrotizing enteritis and hyperammonemic encephalopathy associated with equine coronavirus infection in equids. Vet Pathol 52:1148-56

14. Gorbalenya AE, Baker SC, Baric R, Pulock OS, Aziz TT, Hayee S, Tamanna N, Chuwdhury GS, Haque A, Yeasmin10 F, Akter M. Severe acute respiratory syndromerelated coronavirus: The species and its viruses-a statement of the Coronavirus Study Group. https://doi.org/10.1038/s41564-020-0695-Z

15. Granzow H, Weiland F, Fichtner D, Schütze H, Karger A, Mundt E, Dresenkamp B, Martin P, Mettenleiter TC (2001) Identification and ultrastructural characterization of a novel virus from fish. J GEN VIROL 82:2849-59

16. Hu B, Ge X, Wang LF, Shi Z (2015) Bat origin of human coronaviruses. Virol J 12:221

17. Mihindukulasuriya KA, Wu G, Leger JS, Nordhausen RW, Wang D (2008) Identification of a novel coronavirus from a beluga whale by using a panviral microarray. J VIROL 15:5084-8

18. Munster VJ, Feldmann F, Williamson BN, Van Doremalen N, Pérez-Pérez L, Schulz J, Meade-White K, Okumura A, Callison J, Brumbaugh B, Avanzato VA (2020) Respiratory disease and virus shedding in rhesus macaques inoculated with SARSCoV-2. BioRxiv

19. OIE:https://www.oie.int/en/scientific-expertise/specific-information-and recommendations/questions-and-answers-on-2019novel-coronavirus/ Accessed on 22 Jun 2020

20. Ozma MA, Maroufi P, Khodadadi E Köse Ş, Esposito I, Ganbarov K, Dao S, Esposito S, Dal T, Zeinalzadeh10 E, Kafil HS (2020) Clinical manifestation, diagnosis, prevention and control of SARS-CoV-2 (COVID-19) during the outbreak period. Inf Med 28

21. Pan Y, Zhang D, Yang P, Poon LL, Wang Q (2020) Viral load of SARS-CoV-2 in clinical samples. LANCET INFECT DIS 20:411-2

22. Peeri NC, Shrestha N, Rahman MS, Zaki R, Tan Z, Bibi S, Baghbanzadeh M, Aghamohammadi N, Zhang W, Haque U. February (2020) The SARS, MERS and novel coronavirus (COVID-19) epidemics, the newest and biggest global health threats: what lessons have we learned. Int J Epidemiol

23. Pressman P, Naidu AS, Clemens R. COVID-19 and food safety: risk management and future considerations.

24. Roberts A, Vogel L, Guarner J, Hayes N, Murphy B, Zaki S, Subbarao K (2005) Severe acute respiratory syndrome coronavirus infection of golden Syrian hamsters. J Virol 79:503-11

25. Rothan HA, Byrareddy SN (2020) The epidemiology and pathogenesis of coronavirus disease (COVID-19) outbreak. J Autoimmun 102433

26. Saif LJ (2010) Bovine respiratory coronavirus. Veterinary Clinics: Food Animal Practice. 26:349-64

27. Schwegmann-Wessels C, Herrler G (2006) Transmissible gastroenteritis virus infection: a vanishing specter. DTW. Deutsche tierarztliche Wochenschrift 113:157-9. 
28. Shereen MA, Khan S, Kazmi A, Bashir N, Siddique R (2020) COVID-19 infection: Origin, transmission, and characteristics of human coronaviruses. J Adv Res

29. Shi J, Wen Z, Zhong G, Yang H, Yang H, Wang C, Huang B, Liu R, He X, Shuai L, Sun Z, Zhao Y (2020) Susceptibility of ferrets, cats, dogs, and other domesticated animals to SARS-coronavirus. 368:1016-20

30. Song D, Park B (2012) Porcine epidemic diarrhoea virus: a comprehensive review of molecular epidemiology, diagnosis, and vaccines. VIRUS GENES 44:167-75

31. Vogel L, Van der Lubben M, Te Lintelo EG, Bekker CP, Geerts T, Schuijff LS, Grinwis GC, Egberink HF, Rottier PJ (2010) Pathogenic characteristics of persistent feline enteric coronavirus infection in cats. Vet Res 41:71

32. Wan Y, Shang J, Graham R, Baric RS, Li F (2020) Receptor recognition by the novel coronavirus from Wuhan: an analysis based on decade-long structural studies of SARS coronavirus. J Virol 17:94

33. Wang Q, Vlasova AN, Kenney SP, Saif LJ (2019) Emerging and re-emerging coronaviruses in pigs. CURR OPIN VIROL 34:39-49

34. WHO: https://www.who.int/emergencies/diseases/novel-coronavirus-2019 Accessed on 19 Jun 2020.

35. Woo PC, Lau SK, Lam CS, Tsang AK, Hui SW, Fan RY, Martelli P, Yuen KY (2014) Discovery of a novel bottlenose dolphin coronavirus reveals a distinct species of marine mammal coronavirus in Gammacoronavirus. J Virol 88:1318-31

36. Workman AM, Kuehn LA, McDaneld TG, Clawson ML, Chitko-McKown CG, Loy JD (2017) Evaluation of the effect of serum antibody abundance against bovine coronavirus on bovine coronavirus shedding and risk of respiratory tract disease in beef calves from birth through the first five weeks in a feedlot. Am J Vet Res 78:1065-76

37. Wu Y, Guo C, Tang L, Hong Z, Zhou J, Dong X, Yin H, Xiao Q, Tang Y, Qu X, Kuang L (2020) Prolonged presence of SARS-CoV-2 viral RNA in faecal samples. LANCET GASTROENTEROL 5:434-5

38. Zhang Z, Wu Q, Zhang T (2020) Pangolin homology associated with 2019-nCoV. bioRxiv

39. Zhou D, Cai W, Zhang W (1999) An adaptive wavelet method for nonlinear circuit simulation. IEEE Transactions on Circuits and Systems I: Fundamental Theory and Applications 46:931-8

40. BBC news on tiger showing positive to SARS-CoV-2 infection at Bronx zoo, New York https://www.bbc.com/news/world-us-canada-52177586 Accessed on 21 Jun 2020 